\title{
Centros de ciencia en Colombia: intercambio de conocimiento tácito entre los mediadores y el público en la comunicación de la ciencia
}

Carlos E. Blanco-Valbuena*

Recibido: 25-02-2021

Aceptado: 01-03-2021

\begin{abstract}
Citar como: Blanco-Valbuena, C. E. (2021). Centros de ciencia en Colombia: intercambio de conocimiento tácito entre los mediadores y el público en la comunicación de la ciencia. Revista Interamericana de Investigación, Educación y Pedagogía, 14(2), 317-371. https:// doi.org/10.15332/25005421.6641
\end{abstract}

\section{Resumen}

El artículo presenta las evidencias de conocimiento tácito de los mediadores cuando llevan a cabo la comunicación de la ciencia desde las variables de la cultura organizacional, las cualidades personales y las dimensiones destinadas al intercambio de saberes. Para obtener las certezas del saber ser y el saber hacer de los mediadores, hemos utilizado con ellos el método de entrevistas cara a cara, y definir así las diferentes categorías. La explicitación del conocimiento tácito sirve como guía para el diseño de estrategias que fortalecen la formación de las personas y fomentan el aprendizaje de los ciudadanos. Los centros que participaron en la investigación han sido Maloka, El Planetario Distrital, El Jardín Botánico de Medellín y el Jardín Botánico de Bogotá. Finalmente, se presenta una serie de consideraciones sobre el valor que tiene la codificación del conocimiento tácito, que hasta ese momento ha sido difícil de compartir por permanecer profunda y singularmente arraigado en la mente de las personas $y$, por ello, invisible; pero que de este modo aflora y sirve como insumo para, desde la mediación, ser de utilidad en la gestión de los centros de ciencia.

* Ph.D. en Economía y Dirección de Empresas por la Universidad de Deusto, País Vasco, España. Investigador de la Facultad de Ciencias y Tecnologías, Universidad Santo Tomás, Bogotá, Colombia. 
Palabras clave: centros de ciencia, cultura organizacional, intercambio de conocimiento tácito, mediación, aprendizaje.

\section{Science Centers in Colombia: Exchange of Tacit Knowledge Between Mediators and the Public in the Communication of Science}

\section{Abstract}

This paper presents evidence of the tacit knowledge of mediators when they communicate science from the variables of organizational culture, personal qualities, and dimensions intended to exchange knowledge. To obtain the certainties of the know-how of the mediators, we used face-to-face interviews, and thus defined the different categories. The explicitness of tacit knowledge serves as a guide for the design of strategies that strengthen the training of individuals and encourage citizen learning. The science centers that participated in the research were Maloka, Planetario Distrital, Jardín Botánico de Medellín, and Jardín Botánico de Bogotá. FinaIly, some considerations are presented on the value of the codification of tacit knowledge, which until then had been difficult to share as it remained deeply and uniquely rooted in people's minds, and, therefore, invisible, but that now emerges and serves as an input for the management of the Science Centers through mediation.

Keywords: science centers, organizational culture, tacit knowledge exchange, mediation, learning.

\section{Centros de Ciências na Colômbia: troca de conhecimento tópico entre mediadores e público na comunicação da ciência}

\section{Resumo}

O artigo apresenta evidências do conhecimento implícito dos mediadores quando realizam a comunicação da ciência a partir das 
variáveis da cultura organizacional, qualidades pessoais e dimensões destinadas à troca de conhecimento. Para obter as certezas do saber-ser e do saber-fazer dos mediadores, utilizamos com eles o método de entrevistas presenciais e, assim, definimos as diferentes categorias. A explicitação do conhecimento tópico serve como um guia para o desenho de estratégias que fortaleçam a formação das pessoas e estimulem a aprendizagem dos cidadãos. Os centros que participaram da pesquisa foram Maloka, Planetario Distrital, Jardín Botánico de Medellín e Jardín Botánico de Bogotá. Finalmente, há uma série de considerações sobre o valor da codificação do conhecimento legal que até aquele momento tem sido difícil de compartilhar porque permanece profunda e exclusivamente enraizada na mente das pessoas e, portanto, invisível; mas que dessa forma emerge e serve como um insumo para, a partir da mediação, ser útil na gestão dos Centros de Ciência.

Palavras-chave: centros científicos, cultura organizacional, compartilhamento de conhecimento tópico, mediação, aprendizagem.

\section{Introducción}

Desde hace más de dos décadas, los centros de ciencia (CC) se han convertido en los lugares de la comunicación de la ciencia y la tecnología por excelencia (Cossons, 2006; Delicado, 2009; LaspraPérez, 2013). Uno de los factores clave para lograr que el público sienta interés, motivación y confianza es el encuadre de la interacción con el público, tanto en términos de llegar a los diversos receptores, como el compromiso para desarrollar las habilidades profesionales adecuadas para gestionar dichas interacciones (Bandelli y Konijn, 2012). Para SánchezMora (2004) la relación directa de los mediadores a través de los diálogos con los ciudadanos busca la comprensión de los temas científicos, con el fin de propiciar el acercamiento a las ciencias, generar vocaciones, descubrir, experimentar y despertar los sentidos y las emociones. 
Testa (2006) opina que la comunicación de la ciencia no es una simple difusión, sino más bien un proceso en el que los diferentes actores producen conocimientos, mensajes, actitudes y nuevas prácticas aceptadas por todos.

Según Da Empoli (2006), la relación entre los mediadores y el público, su atención debe ser ganada a partir de la confianza, la motivación y las emociones. Rodari y Merzagora (2007) afirman que los CC deberían implementar nuevas estrategias para captar e involucrar al público en el desarrollo de sus actividades y programas, con el fin de fortalecer su relevancia social y convertirse en actores significativos en el diálogo entre la ciencia y la sociedad. Bandelli y Knij (2012) sugieren que aquellos que trabajan en los centros de ciencia deben ser capaces de construir nuevos escenarios y proyectos sobre el futuro, con la capacidad de autointerrogarse sobre lo que se puede hacer mejor.

La gestión del conocimiento ( $\mathrm{KM}$, por sus siglas en inglés: knowledge management) y la relación con el saberser y saberhacer de los centros de ciencia pone de relieve la importancia de una cultura de intercambio para apoyar y fomentar este enfoque (Alavi y Leidner, 1999; Davenport y Prusak, 1998). La KM se centra en las formas de socializar, externalizar, combinar, internalizar y almacenar el conocimiento del individuo, como medio para mejorar la competencia, la velocidad, la eficiencia y la rentabilidad.

Desde el enfoque de la gestión de conocimiento - haciendo hincapié en el intercambio de conocimiento y sobre todo a partir de las interacciones cara a cara- nos centramos en el conocimiento tácito de carácter cognitivo, que consiste en las creencias, los valores, las actitudes, las intuiciones, las ideas, los mapas mentales y los esquemas que están relacionados con la cultura de las personas y del grupo (Duffy, 2000; Gore y Gore, 1999; Nonaka, 1994). Se cree que la cultura de las organizaciones, en varios niveles, influye en los comportamientos relacionados con el conocimiento de los individuos, los equipos, las unidades gestoras y la organización en general. 
La cultura organizacional ha sido mencionada como el aporte más significativo a la gestión eficaz del conocimiento y el aprendizaje organizacional (Janz y Prasamphanich, 2003). Ladd y Mark (2002, citados en Intezari, Taskin, y Pauleen, 2017) sugieren que los CC son espacios que necesitan desarrollar una cultura sólida que fomente el intercambio de conocimientos entre los mediadores y de estos con el público. Desde el punto de vista de Malhotra (1997), el conocimiento existente en la mente de los miembros de una organización es uno de sus valiosos y mayores recursos. Según Szulanski (2000), como fuente del proceso del intercambio y transferencia de conocimientos, los comportamientos de los transmisores de conocimientos tienden no solo a afectar directamente la adquisición y absorción del conocimiento de los receptores, sino que también se alinean con la eficacia de la transferencia de conocimiento.

La dimensión cognitiva del conocimiento tácito - que se comparte en el intercambio de conocimiento entre los mediadores y el público- lleva muy arraigados ciertos comportamientos que proceden de la endoculturación, la enculturación y la formación/ capacitación de las personas, como lo es la confianza (Goh, 2002; Huener et ál. 1998; Nichani, 2004; Chowdhury, 2005; Ardichvili et ál., 2003; Pacharapha y VathanophasRactham, 2012), la motivación (Lin, 2007; Osterloh et ál. 2002; Lam y Lambermont-Ford, 2010), la identidad, compromiso y lealtad (Ulrich, 1998; Byrne, 2001; Koriat y Gelbard (2014, citados en Curtis y Taylor, 2018), la formación (Baldwin y Ford, 1988; Elangovan y Karakowsky, 1999; lqbal y Dastgeer, 2017) y la apertura a la comunicación (Lin, 2011, p. 139) teniendo un impacto en el intercambio de conocimiento (Wagner y Sternberg, 1985; Nonaka y Takeuchi, 1995; Zollo e Winter, 2002 ; Szulanski y Jensen, 2004; Osterloh et ál. 2002).

Razmerita, Kirchner y Nielsen, (2016) mencionan que, aunque se han llevado a cabo varios estudios sobre los factores que afectan el comportamiento en el intercambio de conocimientos de los mediadores y de estos con otros que podrían ser externos, existen pocos estudios empíricos recientes sobre qué factores 
afectan este comportamiento, que va desde el uso de las redes sociales hasta la comunicación cara a cara.

El documento contribuye a mejorar la comprensión, tanto en las comunidades académicas como en los centros de ciencias, en relación con la percepción y el impacto del intercambio de conocimiento tácito entre los mediadores y el público en la comunicación de la ciencia. Esta contribución académica se debe a que está observando a los centros de ciencia como organizaciones que poseen un conocimiento valioso que se crea continuamente y se comparte con los diversos públicos a partir de diferentes estrategias que nos sirven de ejemplo para la academia y para los procesos de aprendizaje. Consideramos que los resultados les servirán a los directivos para reflexionar y rediseñar las estrategias de formación de los mediadores y valorar aún más el conocimiento tácito cognitivo que poseen estos cuando tienen interacciones cara cara con los ciudadanos.

\section{Revisión de la literatura}

En este apartado abordamos, en primer lugar, la importancia que tienen los centros de ciencia en la sociedad. En segundo lugar, centraremos nuestra atención en la cultura organizacional y el intercambio de conocimiento, para develar las variables que las componen. En tercer lugar, haremos énfasis en el intercambio de conocimiento como una capacidad esencial de las organizaciones. En cuarto lugar, haremos mención al valor del conocimiento tácito. Por último, describiremos las dimensiones culturales asociadas con el conocimiento tácito de carácter cognitivo y que se relacionan directamente con las actitudes, los valores, los modelos mentales y las creencias de las personas que intercambian sus conocimientos con el público dentro de una cultura del conocimiento.

\subsection{Importancia de los centros de ciencia}

Para Delicado (2009), los centros de ciencia tiene como fin informar, formar y entretener a los diferentes públicos; le permiten 
al ciudadano acercarse comprensivamente al proceso que tiene lugar ente el descubrimiento o el avance científicotecnológico, su aplicación social y desarrollar actividades que abren el intercambio de ideas entre científicos en aspectos de la actualidad y la cotidianidad (LaspraPérez, 2013); la visita proporciona una fuerte experiencia emocional, principalmente destinada a facilitar un mapa mental del tema, estimular el interés y fascinar al público (Cossons, 2006); el encuentro de los públicos con los guías tiene valor cuando el conocimiento que intercambian y transfieren a través de la consulta, el diálogo y la participación es de carácter experiencial y social (Macdonald, 1998; Cameron, 2005). El papel de los CC está en que la atención de los ciudadanos debe ser ganada a partir de la confianza, la motivación y despertar el interés y las emociones (Da Empoli, 2006).

Según Bandelli, Konijn y Willems (2009), en estos espacios se están desarrollando nuevas estrategias para involucrar al público más activamente en el aprendizaje de la ciencia de manera informal y responder a la necesidad de presentar la ciencia y la investigación contemporáneas como parte de sus programas públicos. Pretenden ser un vínculo directo entre el público y el hacer ciencia, siendo el centro clave para gestionar las interacciones del público con las partes interesadas (Bell, 2008; Chittenden, 2011; Chittenden, Farmelo y Lewenstein, 2004, citados en Bandelli y Konijn, 2012).

Para LévyLeblond (1992 citado en Bandelli y Konijn, 2012), los CC se han convertido en lugares donde se produce la "comprensión del público por los científicos", gracias a las interacciones cara a cara entre ambos. SánchezMora (2004) advierte que el mensaje entre los guías y los públicos debe ser claro, emocionante y atractivo, para que pueda ser aplicado en la propia vida. Glicken (1999) concuerda con Bandelli et ál. (2012) al ilustrar que las exposiciones transmiten no solo el conocimiento cognitivo - que se basa en la experiencia técnica y está sujeta a un juicio de corrección- sino también al conocimiento experiencial y social basado en las experiencias personales y los valores sociales. 


\subsection{Cultura organizacional $e$ intercambio de conocimiento}

La cultura organizacional encierra los valores, las creencias, las normas y las expectativas ampliamente sustentadas en una organización (Huber, 2001); los valores y artefactos (Shein, 1985); el pensamiento, el habla, la acción y los artefactos, que dependen de la capacidad del hombre para aprender y transmitir el conocimiento a las generaciones venideras (Gurteen, 1999). La cultura organizacional es quizás el obstáculo más significativo para la gestión efectiva del conocimiento (Gold et ál., 2001).

Para De Long y Fahey (2000), la cultura da forma a los supuestos de la gente sobre la importancia del conocimiento y es la base para las percepciones sobre las cuales la cultura también moldea la creación, la adopción de nuevos conocimientos y su distribución por medio de las interacciones entre los diferentes actores. Schein (2004, citado en Intezari, Taskin, y Pauleen, 2017) afirma que la cultura de un grupo es "un patrón de suposiciones básicas compartidas" sobre la adaptación externa y la integración interna. La cultura que apoya el intercambio eficaz de los conocimientos se refiere a las actitudes y las creencias que motivan y animan a los empleados a llevar a cabo activamente la comunicación, la traducción, la conversión y el filtrado para hacer que el conocimiento esté disponible en toda la organización (Newman y Conrad, 2000).

Alavi et ál. $(2005 ; 2006)$ aseveran que crear una organización que funcione como un sistema colaborativo no solo depende de las decisiones individuales, sino que también requiere de un liderazgo evidente. La alta dirección puede ejercer una influencia sustantiva en las actividades de los miembros de la organización, al construir y fomentar las creencias y los valores sobre el significado de la gestión del conocimiento. Solo cuando los altos directivos conducen con el ejemplo y demuestran su disposición a compartir sus conocimientos, pueden desarrollar una cultura compartida.

Para Brand (1998), el conocimiento se mueve sin problemas dentro de la organización solo si las personas están motivadas 
a acceder, compartir la información y las ideas como algo natural, y no porque estén obligadas a hacerlo. Wei (2005) sugiere que la capacidad para dar forma a la cultura organizacional tiene primordial importancia en el fomento de los entornos de aprendizaje. Por su parte, Stoddart (2001) apunta a que el intercambio de conocimientos solo puede funcionar si la cultura de la organización lo promueve.

\subsection{El intercambio de conocimiento como capacidad organizacional}

Gibbert y Krause (2002) definen el intercambio de conocimientos como la voluntad de los individuos de compartir con otros los saberes que han adquirido o creado. Esta definición subraya la importancia de la voluntad. El intercambio de conocimientos no puede ser forzado, sino que solo puede fomentarse y facilitarse. Los factores motivacionales son importantes para compartir el conocimiento.

Van den Hooff y de Leeuw van Weenen (2004) creen que el intercambio de conocimientos incluye tanto la comunicación voluntaria del saber de unos a otros, como la recolección de los conocimientos. Una motivación surge de la creencia de que compartir el conocimiento es útil para la organización, junto con el deseo de ayudar a esta a tener éxito (Hinds y Pfeffer, 2003).

Según Lin (2007), el intercambio de conocimientos a nivel organizativo puede definirse como capturar, organizar, reutilizar y transferir los saberes basados en la experiencia que residen dentro de la organización, y poner este conocimiento a disposición de todos los empleados. Para Yang (2007, citado en Intezari, Taskin y Pauleen, 2017), el intercambio de conocimientos ocurre cuando una persona es capaz y está dispuesta a ayudar a los demás, así como a aprender de otras personas.

El intercambio de conocimientos transmite un flujo bidireccional de saberes; es decir, el intercambio de conocimientos no se limita únicamente a dar información a los demás, también se trata de buscar, 
localizar y absorber el conocimiento. En este sentido, compartir los conocimientos equivale al intercambio de saberes, que consiste en proporcionar a otros el conocimiento de uno y también recibir el de otros (Davenport y Prusak, 1998, citados en Intezari, Taskin, y Pauleen, 2017).

De acuerdo con Lin y Dalkir (2010), los valores organizativos compartidos influyen en la percepción del individuo sobre la propiedad del conocimiento y las tendencias subsiguientes para compartir sus saberes con otros. Además, el intercambio de conocimientos requiere que los miembros de la organización estén dispuestos a aportar sus saberes a la organización (Ajmal y Koskinen, 2008).

Szulanski (2000) expone que, en la fuente del proceso de transferencia de conocimientos, los comportamientos de los transmisores de conocimientos tienden no solo a afectar directamente la adquisición y absorción de los saberes de los receptores, sino que también se alinean con la eficacia de su transferencia. Para Ipe (2003), el intercambio de conocimientos se puede definir como "el acto de hacer que los conocimientos estén a disposición de otros dentro y fuera de la organización".

Menon y Pfeffer (2003) explican que, en el proceso de intercambio de conocimiento, si los transmisores del conocimiento pueden codificar adecuadamente el conocimiento tácito, expresar deliberadamente el conocimiento al receptor de manera fácilmente aceptada y responder a la demanda de conocimiento del receptor a tiempo, pueden promover el intercambio de conocimientos; $y$, por último, aprovechar el intercambio de conocimientos para gestionar con éxito la adherencia al conocimiento.

Según Tangajara et ál. (2016, p. 659):

[...] el intercambio de conocimiento (KS) utiliza perspectivas unidireccionales o bidireccionales La perspectiva unidireccional afirma que KS solo implica la diseminación del conocimiento en una sola dirección, del proveedor 
al destinatario. Esta perspectiva se caracteriza por ser un atributo conductual que tiene como acento una construcción reflexiva.

\subsection{Conocimiento tácito e intercambio de conocimiento}

Nonaka y Takeuchi (1995) expresan que el conocimiento tácito consta de dos partes: una dimensión técnica de saber hacer algo, que no se puede expresar fácilmente, y una dimensión cognitiva de percepciones arraigadas, que influyen en las interacciones diarias de un individuo. Wagner y Sternberg (1985) definieron los conocimientos tácitos como "ese conocimiento práctico relacionado con el trabajo aprendido informalmente en el trabajo". Esta definición precisa solo una parte del conocimiento tácito, es decir, aquella que abarca el "knowhow". La otra parte del conocimiento tácito es la dimensión cognitiva (Beamer y Varner, 2001) que consiste en las creencias, los valores, las actitudes, los ideales, los mapas mentales y los esquemas que están relacionados con la cultural de la persona y del grupo. Esta dimensión cognitiva del conocimiento tácito es la parte más importante, pero a su vez la más difícil, ya que permite la creación y la difusión del conocimiento.

Fleck (1996, p.119) describe el conocimiento tácito como
[...] la forma de conocimiento que está totalmente encarnada en el individuo, arraigada en la práctica y la experiencia, expresada a través de la ejecución hábil, y transmitida por el aprendizaje y la formación a través de la observación y la realización de las formas de aprendizaje.

Para Polanyi (1966), el conocimiento tácito pertenece al dominio personal, pero todavía está plasmado en el encuentro entre el individuo y la cultura a la que pertenece. Por su parte, Tsoukas (2003) destaca que el conocimiento tácito no puede ser capturado, traducido o convertido, sino que solo se muestra y se manifiesta en las actividades. 
Así las cosas, el conocimiento tácito se puede encontrar en las percepciones subjetivas, las intuiciones, los presentimientos y el knowhow, y solo puede ser adquirido a través de la experiencia (Berman et ál., 2002). En esencia, el conocimiento tácito solo existe gracias a las personas y a su habilidad para entender las experiencias de los otros a través del lenguaje común (Canestrino, 2004). Sin embargo, la información solo se vuelve valiosa como conocimiento cuando esta se combina con la experiencia personal. El conocimiento tácito existe por las personas y su habilidad limitada para entender las experiencias de los otros a través del lenguaje en sí mismo (Dougherty, 1999).

Para Lecuona y Reitzig (2014), el conocimiento tácito se hace evidente en las interacciones entre personas que expresan juicios basados en el estilo y la cultura de la organización.

\subsection{Dimensiones culturales $e$ intercambio de conocimiento}

En la revisión de la literatura se han identificado una serie de dimensiones culturales que influyen en el intercambio de conocimientos. Al revisar los diferentes autores, encontramos varias dimensiones culturales, las cuales están relacionadas con la cultura organizacional y el intercambio de conocimiento tácito de carácter cognitivo.

\subsubsection{Confianza}

Para Goh (2002) y Huener et ál. (1998), un alto nivel de confianza en una organización es una condición esencial para fomentar la voluntad de cooperar y facilitar el flujo de conocimiento en esta (Nichani, 2004). Chowdhury (2005) afirma que un fuerte compromiso emocional por parte de los empleados conduce a un sentido de identidad y confianza. Según Goman (2002), la confianza hace más cooperativo el intercambio de conocimiento. Para lograr este objetivo cada miembro de un equipo debe sentirse seguro de que puede confiar en los otros miembros y puede hacer una contribución real. 
De esta manera, los conocimientos, los puntos de vista y los aportes de los miembros del equipo se compartirán entre sí.

De acuerdo con Ardichvili et ál. (2003) y Pacharapha y VathanophasRactham (2012), construir la confianza en una organización es la clave para crear una cultura corporativa orientada al conocimiento, un entorno positivo en el que se aliente a los empleados a tomar decisiones eficientes, productivas e innovadoras.

Las personas con poca confianza tienden a confiar menos en otros y evalúan los motivos y comportamientos de los demás como sospechosos, mientras que las personas con alto nivel de confianza tienden a confiar más en los demás, a ver intenciones honestas y creer en sus comportamientos (Colquitt et ál., 2006; McKnight y Chervany, 2001; Teo y Liu, 2007).

Szulanski (1995) testifica que los receptores de conocimiento desafían y se resisten al intercambio de conocimiento cuando perciben al emisor como no digno de confianza. Por otra parte, para que los conocimientos sean utilizados por otros empleados, el emisor, además de generar confianza, debe tener una sólida reputación dentro de la organización (Foos et ál., 2006; Leyland, 2005).

\subsubsection{Motivación}

De acuerdo con Nahapiet y Ghoshal (1998), el intercambio de conocimientos es un proceso clave para traducir el aprendizaje individual en una capacidad organizativa. Lin (2007) afirma que la motivación implícita para compartir el conocimiento es más efectiva que los motivadores explícitos de la organización, tales como las recompensas y los castigos.

Los aportes de Lam y Lambermont-Ford (2010) están relacionados con definir la motivación extrínseca e intrínseca. La motivación extrínseca puede apoyar la transferencia de conocimiento explícito, que es medible, pero a menudo falla en el caso del conocimiento tácito, debido a su naturaleza intangible y emergente. A menudo, el uso exclusivo de la motivación extrínseca coloca a las personas 
en una postura transaccional, en lugar de una postura relacional con respecto a la organización. Por su parte, la motivación intrínseca facilita la generación y la transferencia de conocimientos tácitos en condiciones en las que falla la motivación extrínseca.

Lindenberg (2001) considera que la motivación intrínseca se divide en dos tipos: la normativa y la hedónica, que interactúan entre sí junto con la motivación extrínseca; esto facilita una coexistencia más completa entre el individuo y el entorno organizativo. La motivación normativa puede ser influenciada por la organización y refuerza la postura motivacional del individuo hacia el intercambio de conocimientos. Esto depende no solo de la promoción del espíritu de intercambio de conocimientos a través de los valores organizativos, sino también del reconocimiento de la contribución de la actitud normativa del individuo hacia el intercambio, que puede basarse en su formación profesional (Lam, 2000).

Para Amabile (1993), la motivación hedónica ha demostrado ser un factor importante que estimula la creatividad y la innovación. La fuerte motivación hedónica induce a un comportamiento en la búsqueda de conocimiento y aumenta el esfuerzo cognitivo para el intercambio de saberes.

Al analizar los aportes de Iqbal y Dastgeer (2017) sobre la relación de la motivación de las personas con la transferencia de la formación en el lugar de trabajo, se encontró que los empleados con mayor autoeficacia y retención presentan una mayor motivación para transferir, lo que, en última instancia, conduce a una mayor transferencia de la capacitación. Los autores definieron la motivación para la transferencia de la formación como el deseo de los aprendices para utilizar los conocimientos, habilidades y destrezas aprendidas en el lugar real del trabajo.

\subsubsection{Lealtad, identidad, compromiso y voluntad}

Según Ulrich (1998), crear un compromiso emocional significa comprometer la energía y la atención emocional de los empleados. Se refleja en cómo los empleados se relacionan entre sí y se sienten 
en la organización. Sin la lealtad, el conocimiento se pierde fácilmente (Byrne, 2001).

Para Koriat y Gelbard (2014, citados en Curtis y Taylor, 2018), la identidad y el compromiso con la propia organización crean estos lazos sociales entre los individuos y sus superiores directos. Dicho compromiso tiene un efecto en la mentalidad psicológica de los trabajadores y en sus resultados organizacionales, que incluyen la cooperación con otros trabajadores y el comportamiento de la ciudadanía organizacional, particularmente en el intercambio de conocimiento. Van den Hooff y van Weenen (2004, citados en Curtis y Taylor, 2018) proporcionan apoyo empírico a la noción de que el compromiso se relaciona positivamente con el intercambio de conocimiento.

Finalmente, para Hansen (1999), existen dos aspectos principales que pueden reflejar el intercambio de conocimiento: la voluntad del intercambio y la capacidad para este.

\subsubsection{Formación y capacitación}

De acuerdo con los postulados de Bhatti y Kaur (2009), la formación es la técnica más fiable para mejorar la productividad organizativa de los empleados. Baldwin y Ford (1988) definieron la transferencia de capacitación como: "el grado en que los aprendices aplican efectivamente los conocimientos, habilidades y habilidades adquiridas en el contexto de capacitación al trabajo". Elangovan y Karakowsky (1999) afirman que el éxito de cualquier programa de formación depende del grado en que los contenidos se transfieran al lugar de trabajo.

lqbal y Dastgeer (2017) estudiaron la vinculación de ciertas características de los aprendices - como la autoeficacia y la retención del entrenamiento- con la motivación para transferir la formación. Al referirnos a la autoeficacia, esta corresponde a la autocreencia en las capacidades para ejercer control sobre los eventos y lograr los objetivos deseados. Las personas que tienen mayor autoeficacia establecen metas más difíciles que aquellas que tienen 
una autoeficacia menor. Tales personas tienden a rendir mejor en la formación y poseen la mayor motivación para aplicar las habilidades y conocimientos aprendidos en el trabajo. Por esta razón, la autoeficacia desempeña un papel importante en la determinación de los resultados del entrenamiento.

Con respecto a la retención, alude a la capacidad del aprendiz para retener el conocimiento, las habilidades y las destrezas entregadas durante el programa de capacitación y formación. Velada et ál. (2007, citados en lqbal y Dastgeer, 2017) señalaron que, con el paso del tiempo, los aprendices se vuelven incapaces y menos interesados en mantener y utilizar los conocimientos que se adquirieron durante un programa de capacitación. Además, si los aprendices retienen el material de capacitación correctamente, estarán motivados para aplicar estos conocimientos, habilidades y destrezas en el trabajo.

De acuerdo con Cunha et ál. (1999), las organizaciones donde se promueve la formación/capacitación desde la cultura experimental dan margen para la experimentación, el ensayoerror, y se promueve la acción -en lugar de la reflexión-como una forma de entender y lidiar con la realidad. Caldwell y O'Reilly (2003) encontraron que el apoyo a la asunción de riesgos y la tolerancia de los errores en las organizaciones con una cultura experimental, eran dos normas culturales que promovían los comportamientos asociados con la aparición de nuevas ideas y su transferencia. Por su parte, Leonard y Swap (2005) identificaron que la experimentación y la resolución de problemas guiadas son formas de transferir conocimientos tácitos profundos denominados inteligencia profunda.

En su estudio, Abdullah, Al Saifi, Dillon y McQueen (2016) hallaron que un número significativo de participantes indicaron que el aprendizaje y la enseñanza pueden desempeñar un papel importante para facilitar el intercambio de conocimientos. Este hallazgo confirma los postulados de Matzler y Mueller (2011 citados en Abdullah, Al Saifi, Dillon y McQueen, 2016), quienes encontraron que la orientación del aprendizaje de un individuo tiene un efecto positivo significativo en el intercambio de conocimientos. 
Esto debido a que la motivación para mejorar las propias habilidades y hacer frente a las dificultades son condiciones necesarias para el aprendizaje, para lo cual el intercambio de conocimientos es el requisito previo.

\subsubsection{Apertura en la comunicación}

Lin (2011, p. 139) define la apertura en la comunicación como "el grado en que los empleados están dispuestos a intercambiar sus ideas y conocimientos con los colegas y los actores externos a la organización". En las organizaciones donde la cultura predominante está basada en la cultura del conocimiento, los empleados se sienten libres de expresar sus nuevas ideas; no temen perder su trabajo debido a la expresión de un pensamiento diferente de lo que es, en general, aceptado en la organización.

La comunicación efectiva tiene dos cabos. El primero es la racionalidad, que en la etapa de planificación ayuda a identificar las oportunidades, pero sobre todo las limitaciones de la comunicación. El segundo, es la capacidad de construir un diálogo con el público, en el que se imagina por un momento la reacción a lo que se dice $y$, en consecuencia, se adapta a la respuesta. La calidad de la comunicación depende en gran medida de la calidad de la relación que se establece con el público.

Según Tsang (2002 y Sun et ál. 2016, citados en Ren, Deng, Liang, 2018), la comunicación es también un proceso de aprendizaje durante el cual los equipos podrían comprender mejor los conocimientos que obtienen. Cuando los miembros del equipo tienen canales de comunicación más amplios, tendrán más oportunidades de saber unos de otros sobre sus necesidades actuales y de las vías aceptables para el intercambio de conocimientos, por lo que los miembros podrían intercambiar conocimientos más fácilmente.

\subsubsection{Variables que facilitan la comunicación de la ciencia}

La comunicación de la ciencia en los CC tiene implícitas algunas variables que deben ser comprendidas, internalizadas y analizadas 
por las personas encargadas de compartir sus conocimientos con los públicos.

\subsubsection{Lenguaje}

La comunicación requiere el uso de un lenguaje compartido. Por lo tanto, se deben evitar los términos técnicos, y cuando no sea posible evitarlos, se debe explicar siempre su significado, incluso cuando pueda parecer banal; por ejemplo, se pueden utilizar analogías, metáforas, cuentos, historias, canciones, mitos, leyendas, etc. (Lawrence, 2006).

\subsubsection{Identificar los problemas de la audiencia}

En términos generales, siempre es necesario recordar que, si bien la comunicación es ante todo un diálogo — que a veces es imaginariocon una audiencia, cualquier explicación debe ir precedida por una comprensión de las dificultades que el público puede encontrarse. Los científicos tienen la gran ventaja de conocer bien el tema, pero la gran desventaja es que para ellos no es tan fácil entender lo que el público podría encontrar difícil. Si los científicos quieren hacerse entender, entonces deben hacer un mayor esfuerzo para convertirse en un observador de su propio tema desde el exterior (Lawrence, 2006).

\subsubsection{El imperativo de ser claro}

Una vez identificado el segmento del público al que se dirigen, no tiene sentido explicarle solo a una parte de ellos y olvidarse del resto. En realidad, cada intercambio se compone de una comunicación en el sentido estricto de la palabra, que implica los contenidos y una metacomunicación que involucra la relación establecida entre el orador y el oyente, y que transmite el espíritu emocional de la comunicación en sí (Lawrence, 2006).

\subsection{Las emociones en la interacción cara a cara}

Según Lawrence (2006), si confrontar los hechos de la realidad es el común denominador de todo tipo de empresa científica, 
despertar emociones es el denominador común de todas las formas de comunicación. Sin duda, ganar la confianza del público y crear sentimientos positivos puede ser más persuasivo que los hechos indiscutibles. Se trata de hacer que los temas que se llevan a los públicos sean atractivos $y$, si es posible, espectaculares o incluso sensacionales - por supuesto, dentro de límites aceptables y éticos-.

De acuerdo con los postulados de Lawrence (2006), el primer paso en cualquier comunicación pública es, por lo tanto, identificar qué emociones ganarán el interés del público. Hay infinitas maneras de brindar emociones sobre un tema; la mejor manera de elegirlas es reconocer sus propias emociones como científico $y$, luego, encontrar el vínculo más cercano posible con su audiencia. Por ejemplo, los sentimientos de asombro en cómo funciona la naturaleza, la curiosidad intelectual, la búsqueda de las respuestas a las preguntas existenciales importantes o a un problema del mundo, el placer de trabajar en áreas especiales y así sucesivamente. Permitir que su propia pasión suceda también ayudará a hacer esa transición fundamental de comunicar algo, típico de la comunicación entre expertos para comunicarse con alguien.

\section{Metodología}

La investigación propuesta sigue los principios investigativos de la teoría fundamentada, que busca desarrollar la teoría inductiva a partir de un proceso sistemático de obtención y análisis de los datos en la investigación social (Glaser y Strauss, 1967). Se considera como una metodología general para el análisis de los datos cualitativos, de la cual se puede originar una teoría emergente. Esta hace referencia a la explicación de un fenómeno delimitado a un contexto particular, que define los conjuntos de las categorías, las subcategorías, las propiedades y las dimensiones relacionadas entre sí, mediante un proceso de descripción, comparación y conceptualización de los datos. 
En virtud de que este en enfoque metodológico se plantea el "método comparativo constante" ${ }^{1}$ como procedimiento para el análisis de los datos, se formularon unas categorías analíticas iniciales a partir de la revisión de la literatura. Estas se propusieron como puntos de comparación entre la información recolectada y la teoría, de forma que, aunque la teoría fundamentada no implica formular el problema de investigación desde el principio, su planteamiento en la presente investigación es una alternativa viable.

El proceso de análisis de los datos aplicado en la investigación sigue parcialmente lo propuesto en la teoría fundamentada, en tanto que se realizó en dos momentos: uno descriptivo y otro relacional. En el primer momento, se realiza la codificación abierta², que propone la asignación de las etiquetas o los códigos a los segmentos de datos. El segundo momento se desarrolla mediante dos procesos de codificación: axial y selectiva.

En la presente investigación se llevó a cabo el proceso de codificación axial, mediante el cual se relacionan las categorías con las subcategorías sobre un eje que enlaza las categorías con sus propiedades y dimensiones.

\subsection{Instrumento}

Para levantar la información, se aplicaron entrevistas semiestructuradas de manera individual. La emergencia sanitaria por la COVID-19 impidió llevar a cabo todas las estrategias propuestas, que incluían adelantar instrumentos complementarios, como, por ejemplo: la observación participante o los grupos focales.

1. En términos metodológicos, esto significa codificar y analizar los datos de manera simultánea para el desarrollo progresivo de ideas teóricas que tengan una estrecha correspondencia con los datos. Lo anterior a través de cuatro etapas: comparación de incidentes aplicables a cada categoría, la integración de las categorías y sus propiedades, la delimitación de la teoría y la escritura de la teoría (Glaser y Strauss, $1967)$.

2. Este tipo de codificación busca identificar en los datos los conceptos, así como sus propiedades y dimensiones. Las propiedades se refieren a las características o atributos de una categoría (por ejemplo, el tipo de respuesta emocional ante la noticia de un diagnóstico de una enfermedad crónica), mientras que las dimensiones hacen referencia a la localización de una propiedad a lo largo de un continuo o rango (por ejemplo, rabia, miedo, tristeza, etc.). 
El instrumento aplicado puede definirse como una técnica de investigación social, en la que se pone en comunicación directa (cara a cara) a un investigador/entrevistador y a un individuo entrevistado. Estas entrevistas se caracterizaron por 1) información cualitativa que expresa las formas de pensar y sentir de los entrevistados y aborda la experiencia de un sujeto en una situación temporalmente delimitada; 2) una metodología centrada en buscar la riqueza (densidad) del material lingüístico de las respuestas de los entrevistados; 3 ) un cuestionario validado y elaborado, antes de su aplicación, con los guías más experimentados, para enriquecer las preguntas, el sentido de estas y profundizar en temas diferentes; 4) un juego de lenguaje pregunta-respuesta cercano a la conversación, teniendo en cuenta la información verbal y no verbal; y 5) un proceso de comprensión espontáneo, con un acceso gradual, sucesivo y dialógico — durante la entrevista- a los significados, valoraciones y representaciones de la realidad que el sujeto entrevistado provee.

En esta investigación, las entrevistas se desarrollaron a través de una plataforma digital, en la cual el investigador principal conversó con cada uno de los entrevistados de manera individual, desarrollando un total de 21 entrevistas entre junio y agosto del 2020. El cuestionario tuvo 25 preguntas, de las que se obtuvieron 475 aportes que se definen como transcripciones. La población de interés fueron los guías/mediadores de diferentes centros de ciencia del país: Maloka, el Planetario de Bogotá, el Jardín Botánico de Medellín y el Jardín Botánico de Bogotá. Los entrevistados fueron profesionales con diferentes años de experiencia y una formación universitaria en carreras como biología, ecología, administración turística, economía, ingeniería mecatrónica, diseño industrial, físi$\mathrm{ca}$, etc. Los centros de ciencia se incluyeron por: estar avalados por Colciencias, constituir un referente para los ciudadanos y elaborar artefactos y servicios para comunicarlos a los ciudadanos a través del intercambio de conocimientos ${ }^{3}$. 


\subsection{Encuadre conceptual}

Después de la revisión de la literatura y de la información recolectada en las entrevistas, se establecieron los conceptos principales para comprender el objeto principal de la investigación relacionado con la comunicación de la ciencia desde los CC.

En relación con la comunicación científica se establecieron cinco constructos temáticos: papel de los centros de ciencia, cultura organizacional, intercambio de conocimiento, conocimiento tácito y aspectos personales (figura 1).

Figura 1. Constructos teóricos identificados en las entrevistas a los mediadores de los centros de ciencia.

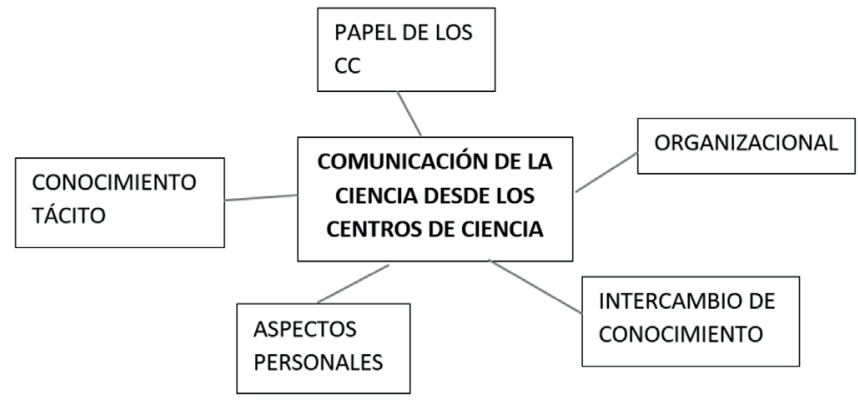

Fuente: elaboración propia.

Cada uno de los constructos se desglosó en dimensiones y categorías. Las dimensiones sirven para desagregar a las categorías, que son necesarias para interpretar los aspectos identificados y el sentido de la información que los entrevistados daban en sus respuestas. Así, se detectaron diez dimensiones y 33 categorías analíticas. A continuación, se explican las consideraciones teóricas para la construcción de las escalas de análisis, las cuales son necesarias para procesar la información en el programa de análisis cualitativo NVivo.

\subsection{Constructos temáticos}

a. Papel de los centros de ciencia: se intentó conocer la opinión de los entrevistados con respecto a la importancia que tienen los 
centros de ciencia para los ciudadanos. Las respuestas recibidas se enfocaron en categorías analíticas expuestas en la discusión de los resultados.

b. Organizacional: la cultura organizacional de los CC fomenta, promueve y facilita - o no- el intercambio de conocimiento con los ciudadanos. Las dimensiones y las categorías se presentan en la discusión de los resultados.

c. Intercambio de conocimiento: buscó analizar los aspectos propios del intercambio de conocimientos con el público. Si bien algunos pueden estar cruzados con las categorías de otros constructos, se analizó de manera independiente en virtud de que la información brindada fue abundante. Se construyeron cuatro categorías que se evidencian en la discusión de los resultados.

d. Conocimiento tácito: este se estableció en la revisión de la literatura y hace referencia a los conocimientos tácitos esenciales del saberser y saberhacer de las personas al comunicar la ciencia a los ciudadanos, los cuales fueron desarrollados y acumulados a lo largo de las experiencias, el ensayoerror, las lecciones aprendidas y los contactos en las organizaciones.

e. Aspectos personales: este tiene relación con las virtudes y las capacidades propias de los mediadores entrevistados. Así, se construyeron dos dimensiones presentadas en la discusión de los resultados.

\section{Discusión y resultados}

Una primera categorización de la información recabada permitió identificar un sentido jerárquico en los sentidos de relación y entre los constructos elaborados. Así, se planteó el siguiente mapa conceptual (figura 2) en el que se organizó el sentido de lectura general que tendrá la descripción de datos presentada en el actual informe: 
Figura 2. Orden de los constructos teóricos identificados en las entrevistas a los mediadores de los CC a partir de una propuesta de interpretación.

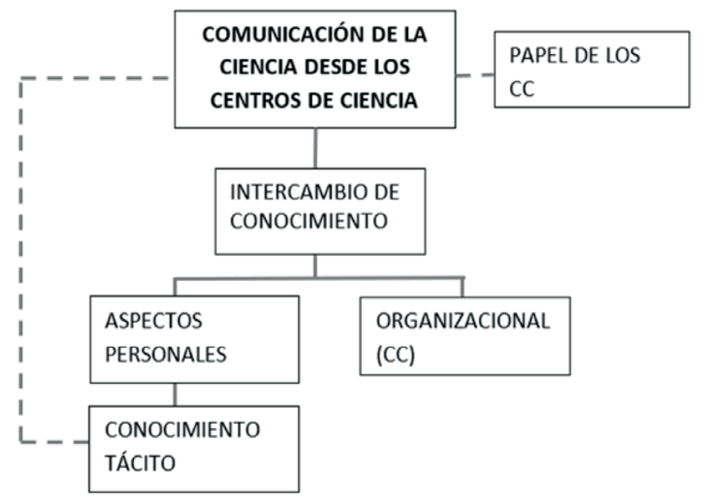

Fuente: elaboración propia.

El mapa conceptual permite comprender que la comunicación de la ciencia desde los CC, estará determinada en parte, por el papel de los centros de ciencia. Los mecanismos y contenidos de la comunicación en ocasiones estarán supeditados, aunque a su vez determinarán el papel que percibe la ciudadanía en relación con el CC.

En una segunda parte de la lectura de los resultados se desarrolla el análisis del constructo intercambio de conocimiento, el cual se considera jerárquicamente superior a los aspectos personales y organizacional, aunque al mismo tiempo se comprende a partir de esos mismos aspectos.

Finalmente, la dimensión conocimiento tácito se considera como parte integrante de los aspectos personales, aunque - de acuerdo con los fines de la investigación - se desarrolla de manera independiente, ya que la información recabada permite comprender el potencial explicativo que tiene este tipo de conocimiento para definir el éxito o fracaso en la comunicación de la ciencia.

A continuación, se abordan cada uno de los constructos temáticos, las dimensiones y las categorías. De igual manera, se identificaron las relaciones entre las categorías y los aportes de los autores referenciados en la literatura. Además, se destaca evidencia sobre los 
conocimientos de los guías/mediadores en la interacción con los públicos a partir del intercambio de conocimiento tácito.

\subsection{El papel de los centros de ciencia}

Teniendo en cuenta la dimensión del papel de los centros de ciencia, se definieron tres categorías de acuerdo con los aportes de los mediadores de las cuatro instituciones, por ejemplo, 1) aprendizaje y competencias ciudadanas; 2 ) aportes a la calidad de vida de los ciudadanos, y 3) el diálogo científico, pensamiento crítico y reflexión.

Con respecto a la primera categoría aprendizaje y competencias ciudadanas, se observa que a través del intercambio de conocimiento tácito por medio de las interacciones cara a cara con los ciudadanos, los mediadores implementan estrategias y mecanismos para que el visitante logre aprender sobre los conocimientos científicos, y al mismo tiempo desarrollen competencias en el uso de estos conocimientos. Este hallazgo está en concordancia con los aportes de Delicado (2009), quien sugiere que los CC deben informar, formar y entretener a los ciudadanos. De igual manera, Bandelli, Konijn y Willems (2009) sugieren que una función de los CC es involucrar al público más activamente en el aprendizaje de la ciencia de manera informal. Se citan varios ejemplos de las transcripciones de los mediadores:

[...] la gente se apropia de los conocimientos para sentirse parte de una ciudad y en el que se crean competencias ciudadanas; la gente se identifique con esas plantas y hace más efectivos esos momentos de aprendizaje; el centro de ciencia es un espacio de aprendizaje, un espacio de conocimiento en donde la gente puede sensibilizarse a través de todo el conocimiento. (Comunicación personal)

En relación con la segunda categoría aportes a la calidad de vida, Bandelli y Knijn (2012) consideran que el resultado del vínculo 
debe darse en la práctica de la ciencia, aunque los autores no mencionan que las interacciones con los públicos deben incidir en la calidad de vida. Este hallazgo es de gran valor, porque en definitiva lo que se espera de los ciudadanos al estar en los CC es que perciban estos espacios como propicios para mejorar su calidad de vida a partir de los conocimientos que descubren, aprenden y apropian. Citamos varios ejemplos de las transcripciones de los mediadores: "EI CC trabaja por mejorar la calidad de vida de los habitantes de Bogotá; El CC les da tranquilidad a partir de una recreación pasiva, es un espacio de cambio, de tranquilidad; Por medio de la ciencia, transforma y mejora la calidad de vida de las personas" (comunicación personal).

En esta categoría, Laspra Pérez (2013) hace hincapié en que los CC son espacios que permiten al ciudadano acercarse comprensivamente el proceso al que tiene lugar el descubrimiento o el avance científicotecnológico, su aplicación social y el desarrollo de actividades. Esto permite el intercambio de ideas entre científicos en aspectos de la actualidad y la cotidianidad.

La tercera categoría, descrita como diálogo científico, pensamiento crítico y reflexión se encuentra que, a partir de las vivencias de los mediadores, estos sienten y perciben que los CC: "fomentan al pensamiento crítico de las personas"; "es un escenario que les permite dialogar de los temas científicos"; "fomentan la reflexión de una manera diferente"; les hace ser más críticos y se fomenta la creatividad y la curiosidad de los niños" (comunicación personal). Este resultado contrasta con lo planteado por Bandelli y Konijn (2012), Rodari y Merzagora (2007), y Cossons (2006) al afirmar que los CC se han convertido en lugares donde se produce la "comprensión del público por los científicos" gracias a las interacciones y a los diálogos cara a cara para compartir las ideas y los saberes. De igual manera, concuerda con lo que encontraron Glicken (1999) y Bandelli et ál. (2012) al observar que las interacciones de los mediadores y el público en los CC deben estar fundamentado en el conocimiento experiencial y social propio de las experiencias personales y los valores sociales. De esta forma, el ciudadano desarrolla el pensamiento crítico - busca verdades, presenta una actitud 
exploratoria, identifica causas y consecuencias, denota curiosidad y contrasta toda la información- desde el cuestionamiento de sus propias experiencias y la relación con los conocimientos científicos.

\subsection{Intercambio de conocimiento}

Con respecto a este constructo temático, se definió la dimensión temática Comunicar el conocimiento al público, con las siguientes categorías: 1) comunicación asertiva, lenguaje y sensibilización; 2) comunicación en doble vía; 3 ) estrategias o mecanismos de sensibilización y motivación con el público; 4) formación e investigación autónoma o socialización con pares; y 5) conocimiento explícito.

Al analizar la primera categoría comunicación asertiva, lenguaje y sensibilización, los mediadores mencionan lo siguiente: "la gente no solamente ve lo que tú dices, la gente también ve la forma en la que tú te expresas, la convicción con la que estás hablando"; "el diálogo debe ser fácil, divertido, cómodo, cotidiano, dinámico para que el visitante se sienta cómodo"; "el mensaje debe ser creíble para que transmita confianza y permita un diálogo" (comunicación personal). Los aportes de esta categoría se relacionan con los planteamientos de Gibbert y Krause (2002), y Lin (2011, p. 139), quienes describen que el intercambio de conocimientos no puede ser forzado, sino que solo puede fomentarse, facilitarse y ser capaz de construir un diálogo con el público, imaginando por un momento la reacción producida con lo que se dice.

En la segunda categoría, comunicación en doble vía, con base en los aportes de los mediadores se observan las siguientes evidencias: "Hay que tener la apertura para entender que la gente tiene unas realidades construidas en procesos de largo plazo y que sobre eso son ellos los que le contextualizan a uno la situación"; "crear un vínculo y así establecer una forma de intercambiar conocimientos, no solo explicando, sino también aprendiendo a escucharlos" (comunicación personal). La interacción que llevan a cabo los mediadores está en concordancia con Tangajara et ál. (2016), 
al discernir que se trata de un proceso de compartir las ideas, la información y el conocimiento a partir de las experiencias; en este contexto es visible la donación y recolección de conocimientos de las dos partes. Desde los aportes de Ipe (2003) y Davenport y Prusak (1998), el intercambio de conocimientos transmite un flujo bidireccional de saberes. Es decir, el intercambio de conocimientos no se limita a dar únicamente información a otros, también se trata de buscar, localizar y absorber el conocimiento.

Con respecto a la tercera categoría, estrategias y/o mecanismos de sensibilización y motivación con el público, se encuentra que los mediadores Ilevan a cabo las siguientes acciones: "Ios mediadores generan confianza con los públicos a partir de una conversación que nace de una pregunta sobre cosas cotidianas, para que se cuestionen sobre lo que saben o están viviendo". "Se parte del conocimiento inicial que tiene el ciudadano y de sus expectativas". "Se utilizan herramientas participativas y experienciales que permitan la conversación". "Se usan palabras sencillas, sin que se pierda la rigurosidad" (comunicación personal). Los aportes de los mediadores concuerdan con los de Van den Hooff y de Leeuw van Weenen (2004), y Gibbert y Krause (2002), al comprender que el intercambio de conocimientos incluye tanto la comunicación voluntaria de los saberes de unos a otros, como la recolección de los conocimientos.

Un aporte que se resalta de los mediadores es el hecho de "estar dispuestos continuamente a diversificar las estrategias, metodologías, buscar técnicas para seguir cautivando al visitante y se traduce en que constantemente se está experimentando y asumiendo riesgos" (comunicación personal). Este hecho se observa en lo que para Yang (2007, citado en Intezari, Taskin y Pauleen, 2017) es intercambio de conocimientos; es decir, cuando una persona es capaz y está dispuesta a ayudar a los demás, así como a aprender de otras personas, de igual manera, asumiendo riesgos y experimentando continuamente (Caldwell y O'Reilly, 2003).

En la cuarta categoría, formación e investigación autónoma y/o socialización con pares, los aportes se basan en que los conocimientos se nutren a partir de: "Un diálogo continuo entre los compañeros 
y tomando de las capacitaciones lo que más complementa ese saber inicial que se tiene, y cómo puede eso mejorar su proceso de enseñanza sobre las plantas"; "profundiza más sobre la capacitación recibida y empieza a ensayar e intentar nuevas cosas y datos que aprendió en esa capacitación" (comunicación personal). Esta forma de actuar de los mediadores corresponde a lo que Davenport y Prusak, 1998 (citados en Intezari, Taskin, y Pauleen, 2017) opinan sobre el intercambio de conocimientos, que no se limita únicamente a dar información a los demás, también se trata de buscar, localizar y absorber el conocimiento. Esta afirmación también corrobora lo que algunos mediadores hacen por su cuenta, al comentar que cuando algo "lo motiva busco más cosas, más relaciones y conexiones con lo cotidiano" (comunicación personal).

La quinta categoría versa sobre el conocimiento explícito. Al respecto, los mediadores opinaron que, en el proceso de intercambio de conocimiento con los ciudadanos, "citan documentos, autores que hayan hablado del tema de la explicación"; "manejan los conceptos"; "comparten los conocimientos que tienen de su formación profesional"; "se preparan mucho para todas las experiencias que tienen" (comunicación personal). Las evidencias confirman lo que Menon y Pfeffer (2003) explican en el proceso de intercambio de conocimiento, donde los transmisores pueden codificar adecuadamente el conocimiento tácito, expresar deliberadamente los saberes al receptor de manera fácilmente aceptada y responder a la demanda de conocimiento del receptor.

\subsection{Conocimiento tácito}

En primer lugar, se dedicará especial atención a la temática denominada descripción y a las categorías respectivas: 1) las cogniciones tácitas (ideales, valores, modelo mental); y 2) las destrezas personales y know how. Luego, se describirá la segunda dimensión temática denominada mecanismos y habilidades, con las correspondientes categorías: 1) lenguaje representativo y vivencias cotidianas; 2) lenguaje no verbal; 3 ) lectura del contexto y del público a nivel grupal e individual; 4) identificación de los conocimientos, 
valoración de la participación y aprendizaje del público; y 5) comunicación asertiva y sensibilización.

Con respecto a las categorías de conocimiento tácito que se han asociado con la dimensión descripción, se encuentran, "las cogniciones tácitas (ideales, valores y modelo mental) y las destrezas personales y know how". Sobre los aportes de los mediadores en cuanto a las cogniciones tácitas, encontramos, por ejemplo: "el amor por la ciencia que le inculcaron en el colegio" y que lo comparte en su trabajo a través de las interacciones con los ciudadanos. Una forma de hacerlo es a través de las metáforas y las historias que construyen y las hacen propias. Un aporte que se relaciona con esta categoría es, por ejemplo: "lo que más tengo en mi cabeza y más intento poner en la práctica es lo que soy como ser humano, esa parte sensible frente a muchas cosas y eso hace que se genere una cercanía con la otra gente". Otra característica que mencionan es que "la gente te vea como un líder y no solamente como alguien que le está dando información". En el caso de la relación con los niños, manifiestan lo siguiente: "la capacidad de identificar la curiosidad en un niño cuando la veo, y si no de tratar de intencionarla". Los mediadores en el diálogo con los públicos muestran que "la sensibilidad o la intuición innatas están presentes todo el tiempo"; "contagiar con mis emociones, contagiar con mi convicción" (comunicación personal). Estas evidencias, se relacionan con las afirmaciones de Nonaka y Takeuchi (1995), y Bennet et ál. (2015).

A continuación, se hace énfasis en la segunda dimensión temática, que se denominó mecanismos y habilidades, a través de la cual los mediadores hacen visibles las interacciones con los ciudadanos. De acuerdo con Lin (2007), el intercambio de conocimientos también puede definirse como una cultura de la interacción social, que denotan los saberes, las experiencias, los mecanismos y las habilidades.

Con respecto a la categoría comunicación asertiva y sensibilización, se destacan las siguientes evidencias: "El uso de un lenguaje cálido, pero respetuoso"; "cuando se le entrega la confianza 
a la gente es más receptiva, se motiva, da sus propias ideas, habla de sus cosas"; "saber hablarles a las personas según quiénes son, niños, adultos mayores" (comunicación personal). Los aportes de los mediadores guardan relación con las afirmaciones de Lin (2011) y Lawrence (2006), quienes destacan que la comunicación se trata como el grado en que los empleados están dispuestos a intercambiar sus ideas y conocimientos con los colegas y con los actores externos a la organización.

Al hacer referencia a la categoría lenguaje representativo y vivencias cotidianas, los mediadores adoptan formas representativas para que los ciudadanos tengan una mejor comprensión de los temas. Por ejemplo, el uso de las metáforas, mitos, leyendas, canciones, refranes, cuentos, poesías, historias, vivencias, analogías y ejemplos cotidianos para se recuerde o se aprenda de mejor manera lo compartido. Los aportes están relacionados con los siguientes ejemplos: "los mitos y las leyendas hacen parte de la identidad cultural y ayudan mucho a establecer límites en la relación con la naturaleza porque los mitos permiten crear respeto hacia ciertos lugares" (comunicación personal). Estos aportes coinciden con lo que Huan, Yongyuan, Sheng y Qinchao, (2017) expresan sobre el uso del lenguaje representativo para lograr la articulación del conocimiento, cuando se refieren a la medida en que los saberes pueden expresarse claramente al escribir, verbalizar y articular.

Para la categoría del lenguaje no verbal, el intercambio de conocimiento tácito les permite a los mediadores conocer más de cerca a los ciudadanos y facilitar la comunicación en las dos direcciones. Al respecto se encuentra, por ejemplo: "leo las expresiones de las caras"; se está haciendo la actividad se notan las expresiones y se pueden leer"; "Las posiciones corporales, dicen cómo se sienten y qué grado de interés que tienen frente a lo que se les dice" (comunicación personal).

De acuerdo con los aportes de Polanyi (1966), el conocimiento tácito pertenece al dominio personal, pero todavía está plasmado en el encuentro entre el individuo y la cultura a la que pertenece. Tomando en cuenta esta afirmación, los mediadores han desarrollado 
habilidades para: leer el contexto y al público al relacionarlo con la cultura a la que pertenecen. De esto modo se encuentran algunos aportes que dan fe de esta relación, por ejemplo: "entender que cada grupo de personas, cada persona y cada territorio son muy particulares"; "he tratado de llegarles desde la comprensión de sus contextos, entender de dónde vienen" (comunicación personal).

\subsection{Cultura organizacional}

En este apartado se abordan dos dimensiones, la primera relacionada con la promoción del intercambio de conocimiento, y la segunda con la formación y la capacitación centros de cienciamediadores y mediadores-mediadores.

A continuación, se describen las categorías de la primera dimensión.

\subsubsection{Valores y principios organizacionales}

De acuerdo con los aportes de Stoddart (2001), el intercambio de conocimientos solo puede funcionar si la cultura de la organización lo promueve. Como ejemplos se encuentran: "Hacer las cosas con amor y con gusto, carisma, confianza, motivación, compromiso, sentido de pertenencia, reconocimiento del otro, respeto, honestidad, responsabilidad ambiental" (comunicación personal). En opinión de Newman y Conrad (2000), la cultura que apoya el intercambio eficaz de los conocimientos se refiere a las actitudes y las creencias que motivan y animan a los empleados a llevar a cabo activamente la comunicación, la traducción, la conversión y el filtrado para hacer que el conocimiento esté disponible. Huber (2001) concluye que la cultura organizacional encierra los valores, las creencias, las normas y las expectativas ampliamente sustentadas en una organización y que se reflejan en las personas que la componen. 


\subsubsection{Comunicación, liderazgo y deseo por compartir el conocimiento}

Para Van den Hooff y Leeuw van Weenen (2004) el intercambio de conocimientos incluye tanto la comunicación voluntaria del conocimiento de uno a otro, como la recolección de saberes. Estos aportes concuerdan con las evidencias de los guías, por ejemplo: "Debe existir sinergia grupal, las relaciones interpersonales, las redes de conocimiento y la cercanía con el ciudadano" (comunicación personal).

\subsubsection{Confianza en el conocimiento}

El principal hallazgo en esta categoría es que la confianza en el conocimiento no solo viene dada por los saberes explícitos adquiridos por la profesión, sino también por las formaciones complementarias a nivel personal o institucional, y por la fluidez que con que se intercambian los conocimientos a las personas. Los guías dan como ejemplo: "La actitud y la motivación son imprescindibles para tener más confianza en el discurso" (comunicación personal). Esta evidencia tiene relación con los aportes de Chowdhury (2005), quien afirma que un fuerte compromiso emocional por parte de los empleados conduce a un sentido de identidad y confianza. Además, Goman (2002) sugiere que la confianza hace más cooperativo el intercambio de conocimiento.

\subsubsection{Estrategias o mecanismos de sensibilización y motivación}

En este sentido Brand (1998) opina que el conocimiento se mueve sin problemas dentro de la organización solo si las personas están motivadas a acceder y compartir la información. Tenemos como ejemplos: "Redes de conocimiento, ejemplos de otras personas del centro con mayor antigüedad o ejerciendo otros roles relacionados, espacios para compartir entre mediadores/guías, ser receptivos, adecuado manejo del público, articulación entre las áreas y diálogos desde la cotidianidad" (comunicación personal). 
Dentro de las estrategias mencionadas encontramos los siguientes niveles:

1. Nivel personal para el público: hace referencia a la empatía, al respeto, al diálogo cotidiano, a la buena disposición y a la actitud receptiva; entender que el conocimiento no es absoluto, sino que hace parte de una visión abierta al diálogo; y la habilidad para identificar el punto de vista del público y complementarlo con el conocimiento del mediador.

2. Nivel grupal para el público: corresponde a la interacción constante con otros medidores para tener habilidades y destrezas que nutran las conversaciones con el público; y tener conocimiento sobre los temas y estilos de los demás mediadores para que el público experimente de manera integral en la visita y no como un escenario fragmentado.

3. Nivel personal con los mediadores: ser partícipes o tener iniciativa sobre la construcción de redes de conocimiento, entender que el saber no es absoluto, sino que hace parte de una visión abierta al diálogo en donde la interacción entre mediadores siempre será un ingrediente clave.

4. A nivel grupal con el centro de ciencia: procesos de articulación entre áreas, creación de artefactos que impliquen recursos para materiales, entre otros; apoyo e involucramiento en las discusiones entre mediadores para la definición y puesta en marcha de estrategias; y establecimiento de mecanismos de comunicación entre los equipos.

La segunda dimensión está representada por las categorías: estrategias o mecanismos de sensibilización y motivación entre mediadores; espacios formales de formación y de relacionamiento con el público; espacios informales entre mediadores; autoformación o socialización con pares; y los efectos en el fomento de la comunicación. 


\subsubsection{Estrategias o mecanismos de sensibilización y motivación entre los mediadores}

En esta categoría se obtuvieron las siguientes evidencias:

[...] la realimentación, donde surgen los comentarios para entender los diferentes puntos de vista; valoramos la estrategia denominada 'hacer sombra', que consiste formar a las personas principiantes en al cuidado y acompañamiento de una persona más antigua, se apoyan entre sí, para mejorar las actividades y lograr más confianza. (Comunicación personal)

Estos ejemplos coinciden con Tsang (2000) y Sun et ál. (2016, citados en Ren, Deng, Liang, 2018), quienes indican que la comunicación también es un proceso de aprendizaje, durante el cual los equipos podrían comprender mejor los conocimientos que obtienen. Cuando los miembros del equipo tienen canales de comunicación más amplios, tendrán más oportunidades de saber unos de otros sobre sus necesidades actuales y sobre las vías aceptables para el intercambio de conocimientos. Por su parte Lin (2007), afirma que la motivación implícita para compartir el conocimiento es más efectiva que los motivadores explícitos de la organización, tales como las recompensas y los castigos.

\subsubsection{Espacios formales de formación y de relacionamiento con el público}

Los mediadores revelan que en los Centros de Ciencia se fomenta el pensamiento integral, se llevan a cabo inducciones, se desarrollan investigaciones, reuniones virtuales, reuniones entre áreas, a veces se juntan entre otras áreas para apoyarlas, trabajo en equipo, construyen metodologías, asisten a congresos, seminarios y charlas externas. (Comunicación personal).

Según Abdullah, Al Saifi, Dillon y McQueen (2016), este tipo de relaciones conducen a una mayor comunicación, a construir lazos 
sociales y a mejorar la cooperación, todos vitales para estimular el intercambio de conocimientos. Cunha et ál. (1999) testifica que en las organizaciones donde se promueve la formación/capacitación desde la cultura experimental, tienen un margen para la experimentación y el ensayoerror, y se promueve la acción en lugar de la reflexión como una forma de entender y lidiar con la realidad.

\subsubsection{Espacios informales entre los mediadores}

Los aportes de los mediadores en esta categoría hacen visibles las formas y modos en los que comparten los conocimientos en los espacios informales. Por ejemplo:

[...] conversan alrededor de las prácticas, las dudas y valoran los encuentros porque aprenden de forma constante. Algunos mediadores ven al equipo como una familia que se fortalece a través de las risas, apoyado por el área de recursos humanos con el fin de estar más unidos (Comunicación personal)

Estas evidencias concuerdan con los aportes de Osterloh y Frey (2000), en los que el intercambio de conocimientos implícitos y tácitos puede ser facilitado por la motivación intrínseca, como la sociabilidad, la amistad y el compañerismo.

\subsubsection{Autoformación o socialización con los pares}

Esta categoría debía responder a la pregunta: de la capacitación recibida, ¿logró interiorizar los temas, retener los aprendizajes y tener un dominio de la autoeficacia? Al respecto, se identificaron las siguientes evidencias: "La capacitación no es todo, así que logramos ser autoeficientes gracias a la capacidad de autoaprendizaje y de información"; "La parte de la autoeficacia, surge más como un ejercicio personal que de la capacitación, requiere de un tiempo, que no se logra en un taller, en un momentico" (comunicación personal).

Al relacionar esta categoría con la motivación de las personas y la transferencia de la formación/capacitación en el lugar de trabajo, se encontró que los empleados con mayor autoeficacia y retención 
presentan una mayor motivación para transferir los conocimientos (lqbal y Dastgeer, 2017).

\subsubsection{Efectos en el fomento de la comunicación}

Cuando se pregunta sobre un supuesto centro de ciencia en el que la poca confianza hace parte de la interacción entre compañeros, el resultado predominante es que esto afecta considerablemente la interacción con el ciudadano, la transmisión de los conocimientos $y$, por ende, la imagen del centro frente al público.

Por consiguiente, la falta de confianza no es un asunto menor. Al respecto, se destacan los siguientes efectos en la comunicación entre los mismos mediadores y entre mediadores y el público: "Cuando el equipo no trabaja en conjunto, termina haciendo un contacto con la gente desde lo personal y no desde el Centro de Ciencia"; "se notaba más la inseguridad de las personas y los visitantes preferían no entrar"; "generaría un problema en consolidar los canales de comunicación entre los compañeros"; "se pierde asertividad en la comunicación y precisión, porque si no estamos todos de acuerdo o no estamos diciendo lo mismo, puede haber comunicaciones imprecisas" y "se frenaría el diálogo de saberes" (comunicación personal).

Las evidencias anteriores conducen a tener en cuenta la opinión de Szulanski (1995), quien afirma que, si una fuente de conocimiento no es percibida como digna de confianza, su consejo y su conocimiento podrían ser más abiertamente desafiados y resistidos. Para Iftikhar, Eriksson y Dickson (2003) los empleados de una organización que tienden a compartir sus conocimientos con otros dependen, en gran medida, de la magnitud a la que se sientan confiados y confíen en los colegas y los gerentes.

\subsection{Aspectos personales}

En este apartado se abordan las dimensiones y categorías relacionadas con el constructo temático denominado aspectos personales. Aquí se hace referencia a aquellos aspectos que hacen 
parte de la personalidad de los mediadores. Se seleccionaron tres dimensiones de la literatura: la primera es el estímulo económico, la segunda es la motivación y la tercera es la lealtad, la identidad, el compromiso y la voluntad.

\subsubsection{Estímulo económico}

La dimensión estímulo económico tiene dos categorías, a saber: 1) estimulante; 2 ) indiferente o sin estímulo.

\subsubsection{El estímulo económico motivante}

Las razones que exponen los mediadores al percibir el estímulo económico como motivante, corresponden a un bien necesario, y sobre todo por las condiciones laborales en las que desarrollan la actividad. Los mediadores son vinculados a través de un contrato por prestación de servicios anual, lo que los hace incurrir en gastos que implican una disminución considerable en su sueldo; por consiguiente, el pago efectivo no corresponde a la responsabilidad y el tiempo de la labor. Para Lam y Lambermont-Ford (2010), la motivación extrínseca puede apoyar la transferencia de conocimiento explícito - que es medible- pero a menudo falla en el caso del conocimiento tácito, debido a su naturaleza intangible y emergente. A menudo, el uso exclusivo de la motivación extrínseca coloca a las personas en una postura transaccional, en lugar de una postura relacional con respecto a la organización.

\subsubsection{Estímulo económico indiferente}

En relación con este tipo de estímulo económico, cabe señalar que los incentivos financieros no constituyen un estímulo para los mediadores, porque las motivaciones principales en su labor están dadas por los siguientes aportes: "seguir aprendiendo, ascendiendo e impactando con la labor desarrollada"; "Ios comentarios positivos de los colegas y la respuesta de agrado con la visita"; "recibir conocimiento por el centro y/o el público"; "pasión y deseo de enseñar", "contacto con el público y la oportunidad de trabajar en un escenario como un centro de ciencia" (comunicación personal). 
Con todo lo anterior, el conjunto de opiniones frente a este aspecto se resume con una frase entregada por un mediador, quien menciona que "El tema financiero es un elemento influenciador, más no motivador". Los aportes se relacionan con lo que opina Amabile (1993), al considerar que la fuerte motivación hedónica induce a un comportamiento en la búsqueda de conocimiento y aumenta el esfuerzo cognitivo para el intercambio de saberes.

\subsubsection{La motivación}

Las categorías que se hallaron con base en los aportes de los mediadores fueron las siguientes: 1) motivación profesional; 2) creación de artefactos; y 3) pasión por la labor y compromiso de transmitir conocimiento.

\subsubsection{Motivación profesional}

Esta categoría hace referencia a la pregunta: ¿se siente automotivados para intercambiar sus conocimientos con los ciudadanos desde la buena voluntad, la buena actitud y la creatividad?

Los entrevistados concluyeron que la labor como mediador los motiva, porque contribuye a su desarrollo profesional y al mismo tiempo los nutre de conocimientos y habilidades para compartirlos con los ciudadanos. Según los aportes de los mediadores y en concordancia con Amabile (1993), la motivación hedónica ha demostrado ser un factor importante que estimula la creatividad y la innovación. Como evidencia se encuentran los siguientes testimonios: "Estoy en Maloka y sigo en Maloka porque todos los días aprendo algo, me automotiva el poder hacer una carrera en Maloka y escalar un poco más". "A veces me la paso el día estudiando para hacer algo mejor al otro día". "La decisión de hacer un diplomado en pedagogía fue a raíz de mi trabajo", "el valor más importante desde el conocimiento" (comunicación personal).

\subsubsection{Motivación para la creación de artefactos}

La labor de los mediadores en los centros de ciencia los lleva a que se inspiren constantemente, a pensar en cómo llegar a las personas 
de una manera diferente y a construir conocimientos y productos acordes con la realidad. De esta manera, se observa que la creatividad se hace visible en el diseño de cajas de herramientas y la propuesta de nuevos proyectos, juegos, talleres, avisos, contenidos pedagógicos más pertinentes, test, textos, bibliografías, infografías, maquetas y cartillas. En la temporada de aislamiento obligatorio y preventivo, la automotivación en cuanto a lo laboral se incrementó porque, en palabras de ellos mismos, se ha dado la oportunidad de "crear muchas cosas, nos han dado rienda suelta, tenemos la posibilidad de crear, intentar, inventar y hacer esas cosas que en algún momento no pudimos" (comunicación personal). Estos aportes concuerdan con Iqbal y Dastgeer (2017), al asentir que la motivación para la transferencia de la formación tiene relación con el deseo de los aprendices de utilizar los conocimientos, habilidades y destrezas aprendidas en el lugar real del trabajo.

\subsubsection{Pasión por la labor al compartir el conocimiento}

La tercera categoría que se identificó a partir de los aportes de los mediadores está relacionada con la pasión, la emoción y el amor cuando se lleva a cabo el intercambio de conocimientos con los ciudadanos. En los siguientes extractos de las transcripciones de las entrevistas proporcionan se evidencia esta categoría: "Este trabajo lo hago por amor desde hace 10 años, es porque es un lugar que me apasiona, aunque haya días complicados o situaciones que nos indisponen". "Me emociona saber de algo y hablar de ello con las personas, la pasión la transmito con el asombro con el que aún veo las cosas", "cuando uno se emociona, permite que la comunicación esté atravesada por la confianza", "Cuando a uno lo apasiona algo es más fácil transmitir ese conocimiento y esa pasión". "Esos conocimientos me apasionan y yo quiero que la gente sienta esa misma pasión" (comunicación personal).

Las evidencias anteriores concuerdan con los aportes de Lawrence (2006) al afirmar que al permitir que su propia pasión suceda también ayudará a hacer esa transición fundamental de "comunicar algo", típico de la comunicación entre expertos a "comunicarse con alguien", como es el caso con los ciudadanos. 


\subsubsection{La lealtad, la identidad, el compromiso y la voluntad}

Esta tercera dimensión tiene las siguientes categorías: 1) valores y principios personales; 2) entrega y acciones con el ciudadano; y 3) cumplimiento de la misión del centro de ciencia.

\subsubsection{Valores y principios personales}

En esta categoría se encuentra que la buena actitud, la voluntad y la creatividad están presentes en las acciones diarias de los mediadores en el intercambio de conocimiento tácito/explícito con los ciudadanos; por ejemplo: "el respeto entre los compañeros y con el ciudadano"; "la responsabilidad con la información que entrega"; "el llegar puntual al trabajo y los encuentros con los públicos"; "la transparencia, la honestidad y el compromiso hacen parte de los valores y principio" (comunicación personal).

\subsubsection{Entrega y acciones con el ciudadano}

Esta categoría refleja las acciones, intenciones y comportamientos que tienen los mediadores con los ciudadanos cuando se realizan el intercambio de conocimiento. Los entrevistados comentan que es "esencial escuchar a los ciudadanos, darles soluciones e interesarlos, son acciones que deben estar presentes en todo momento de la interacción"; "lo más relevante es que la experiencia que tengan sea una experiencia vivida, no una experiencia escuchada donde el intérprete da la carreta, cuenta y muestra lo que sabe".

Estos aportes tienen relación con las opiniones de Lin (2011) sobre la comunicación, cuando afirma que es la capacidad de construir un diálogo con el público, en el que se imagina por un momento la reacción a lo que se dice y, en consecuencia, se adapta a la respuesta.

\subsubsection{Cumplimiento de la misión del centro de ciencia}

Esta categoría se identificó en los mediadores cuando se les preguntó: ¿cómo en su trabajo manifiestan la lealtad con los ciudadanos? 
Los aportes están en relación "con la misión al sentirse identificados con las líneas estratégicas del CC, siendo conscientes que representan una entidad que estiman, quieren y, por eso, fluye el conocimiento". "El hacer está basado y articulado con lo que es la entidad y en el intercambio de conocimientos con el ciudadano se debe brindar una información verídica, siendo congruentes con lo que se dice, transmitir la verdad y no desarmar la confianza que tienen los directivos" (comunicación personal). Estos aportes se ajustan con Ulrich (1998), quien afirma que crear un compromiso emocional significa comprometer la energía y la atención emocional de los empleados. Se refleja en cómo los empleados se relacionan entre sí y se sienten en la empresa; sin lealtad, el conocimiento se pierde fácilmente (Byrne, 2001). Para reafirmar esta relación se destacan los postulados de Koriat y Gelbard (2014, citados en Curtis y Taylor, 2018), quienes encuentran en la identidad y el compromiso con la propia organización una manera de crear lazos sociales entre los individuos, sus superiores directos y los ciudadanos.

\subsubsection{Autoeficacia}

A esta dimensión le corresponden las siguientes categorías: 1) reflexión personal y mejora constante; y 2) satisfacción por la misión cumplida de transmitir el conocimiento.

\subsubsection{Reflexión personal y mejora constante}

Esta categoría intenta responder a la pregunta: ¿desde la autoeficacia se plantea objetivar metas más difíciles con el fin de que el intercambio de conocimiento tácito con los ciudadanos sea útil y constructivo? Los aportes que se valoraron son: "ponerse metas más altas para hacer las labores de manera diferente y cómo llegar a las personas"; "el desarrollo de la tolerancia y el estar siempre abierto a cada una de las conversaciones con los públicos, ser recursivo"; "practicar la autoevaluación para mejorar constantemente, aceptar los errores como un aprendizaje y darles una solución inmediata, aceptar que las falencias son oportunidades de aprendizaje y el miedo es el primer enemigo del conocimiento" (comunicación personal). Las evidencias conducen a mencionar a lqbal y Dastgeer (2017), 
quienes consideran que las personas que tienen mayor autoeficacia establecen metas más difíciles que las personas que tienen una menor autoeficacia. Tales personas son más propensas a rendir mejor en la formación y poseen la mayor motivación para aplicar habilidades y conocimientos aprendidos en el trabajo.

\subsubsection{Satisfacción por la misión cumplida de transmitir el conocimiento}

Los siguientes extractos de las transcripciones de la entrevista proporcionan evidencias sobre la satisfacción de los mediadores por la misión cumplida de transmitir el conocimiento: "Sí existe una motivación y pienso que es cuando yo recuerdo las buenas experiencias que he vivido al intercambiar experiencias con los ciudadanos; lo que a mí como persona me motiva son los comentarios positivos de los compañeros, recibir el reconocimiento de su jefe y hasta el reconocimiento de los propios visitantes".

\section{Conclusiones}

A continuación, se presentan las conclusiones de la investigación realizada:

- La comunicación que realizan los mediadores de la ciencia hacia los ciudadanos por medio del intercambio de conocimientos tácitos y explícitos lleva impresa la motivación, la sensibilidad, la reflexión, la confianza y el diálogo bidireccional, empleando un lenguaje representativo, como, por ejemplo, las metáforas, las analogías, las historias, los cuentos, las canciones, las leyendas y los mitos. El fin de la interacción es acercar, interesar y actualizar a los ciudadanos, para que desarrollen competencias y aprendizajes destinados a mejorar la calidad de vida.

- La cultura organizacional de los centros de ciencia es visible en la interacción de los mediadores con los públicos cuando se promueve compartir los conocimientos en los 
espacios informales, el trabajo en equipo, los talleres, el desarrollo de artefactos, la formación y la visibilidad de la misión. La confianza entre los diferentes actores (directivos y mediadores) fomenta la cooperación y los puntos de vista.

- Finalmente, la visibilidad del conocimiento tácito en las interacciones de los mediadores con los públicos se evidencia cuando la sensibilidad, la intuición, las emociones, el amor por la labor y las convicciones se comparten y se recrean.

\section{Recomendaciones}

A continuación, se presentan algunas recomendaciones que se deben tener en cuenta por los directivos de los centros de ciencia y por los académicos.

- Los centros de ciencia son espacios propicios para hacer visible la creatividad, porque el intercambio de conocimiento entre los mediadores y los ciudadanos es un continuo compartir de saberes tácitos, que sirven como insumo para proponer diferentes estrategias para el aprendizaje y la práctica de la ciencia en la cotidianidad. Por este motivo, es esencial que los directivos de estas instituciones fomenten los encuentros entre los mediadores después de las experiencias y las vivencias, para que el conocimiento no se quede en la mente de las personas, sino que sea evidente y se pueda reutilizar.

- La tarea de los directivos y los mediadores en cuanto a la explicitación del conocimiento tácito debe ser un reto para que este no se pierda cuando las personas cambien de trabajo o cuando decidan dejar la organización. La riqueza de este conocimiento es la que imprime la valía de la 
comunicación de la ciencia y deja huellas en los que escuchan, aprenden y la practican.

- A los académicos que deseen incursionar en el estudio de la gestión de los centros de ciencia se les sugiere ahondar sobre los procesos de aprendizaje y absorción de conocimiento, para que relacionen estas formas y modos con lo que ellos mismos hacen en el aula.

\section{Agradecimientos}

En esta investigación colaboraron los directivos y mediadores de los cuatro centros de ciencia en Colombia: Sigrid Falla, Liliana Romero, Tatiana Olarte, Kelly Pulido, Alexander Avellaneda y Wilson Cruz (Maloka). Carlos Augusto Molina, Juan Cuervo, Oscar Montenegro, Wyndy Ruiz, Pablo Martínez, Alexander González, Sebastián Benavides, Sebastián Corredor, Stefania Rodríguez (El Planetario de Bogotá). Claudia Lucía García Orjuela, Susana Prieto Bravo, Andrés Felipe Cañas, Javier Nicolás Bernal, Norberto López, Ana María Benavides (Jardín Botánico de Medellín). Tania Rodríguez, Patricia Velázquez, Andrés Vargas (Jardín Botánico de Bogotá).

\section{Referencias}

Abdullah, A., Dillon, S. y McQueen, R. (2016) The relationship between face to face social networks and knowledge sharing: An exploratory study of manufacturing firms. Journal of Knowledge Management, 20(2), 308326. https://doi.org/10.1108/JKM-07-2015-0251

Ajmal, M. M. y Koskinen, K. U. (2008). Knowledge Transfer in ProjectBased Organizations: An Organizational Culture Perspective. Project Management Journal, 39(1), 7-15. https://doi.org/10.1002/pmj.20031 
Alavi, M. y Leidner, D. E. (2001). Review: Knowledge Management and Knowledge Management Systems: Conceptual Foundations and Research Issues. MIS Quarterly, 25(1), 107-136. https://doi.org/10.2307/3250961

Alavi, M., Kayworth, T. R. y Leidner, D. E. (2005-2006). An Empirical Examination of the Influence of Organizational Culture on Knowledge Management Practices. Journal of Management Information Systems, 22(3), 191-224. https://doi.org/10.2753/MIS0742-1222220307

Alavi, M. y Leidner, D. (1999). Knowledge Management Systems: Issues, Challenges, and Benefits. Communications of the Association for Information Systems, 1(5). https://doi.org/10.17705/1CAIS.00107

Amabile, T. M. (1993). Motivational synergy: Toward new conceptualizations of intrinsic and extrinsic motivation in the workplace. Human Resource Management Review, 3(3), 185-201. https://doi.org/10.1016/10534822(93)90012-S

Ardichvili, A., Page, V. y Wentling, T. (2003). Motivation and Barriers to Participation in Virtual Knowledge-Sharing Communities of Practice. Journal of Knowledge Management, 7, 64-77. https://doi. org/10.1108/13673270310463626

Baldwin, T. T. y Ford, J. K. (1988). Transfer of Training: A Review and Directions for Future Research. Personnel Psychology, 41(1), 63-105. https://doi.org/10.1111/j.1744-6570.1988.tb00632.x

Bandelli, A., Konijn, E. A. y Willems, J. W. (2009). The need for public participation in the governance of science centers. Museum Management and Curatorship, 24(2), 89-104. https://doi.org/10.1080/09647770902857497

Bandelli, A. y Konijn, E. A. (2012). Science Centers and Public Participation: Methods, Strategies, and Barriers. Science Communication, 35(4), 419448. https://doi.org/10.1177/1075547012458910

Beamer, L. y Varner, I. (2001). Intercultural Communication in the Global Workplace. McGraw-Hill. 
Bennet, A., Bennet, D. y Avedisian, J. (2015). The Course of Knowledge: A 21st Century Theory. MQIPress Knowledge Series.

Berman, S. L., Down, J. y Hill, C. W. L. (2002). Tacit knowledge as a source of competitive advantage in the National Basketball Association. Academy of Management Journal, 45(1), 13-31. https://doi.org/10.5465/3069282

Bhatti, M. A. y Kaur, S. (2010). The role of individual and training design factors on training transfer. Journal of European Industrial Training, 34(7), 656-672. https://doi.org/10.1108/03090591011070770

Brand, A. (1998). Knowledge management and innovation at 3M. Journal of KnowledgeManagement, 2(1), 17-22. https://doi.org/10.1108/ EUM0000000004605

Byrne, R. (2001). Employees: capital or commodity? The Learning Organization, 8(1), 44-50. https://doi.org/10.1108/09696470110366534

Caldwell, D. F. y O'Reilly, C. A. (2003). The determinants of team-based innovation in organizations: The Role of Social Influence. Small Group Research, 34(4), 497-517. https://doi.org/10.1177/1046496403254395

Cameron, F. (2005). Contentiousness and shifting knowledge paradigms: The roles of history and science museums in contemporary societies. Museum Management and Curatorship, 20(3), 213-233. https://doi. org/10.1016/j.musmancur.2005.05.002

Canestrino, R. (2004). Cross-border knowledge transfer in international strategic alliances: from cultural variations to asymmetric learning process. Proceedings of I-KNOW '04. http://citeseerx.ist.psu.edu/ viewdoc/download?doi=10.1.1.138.4935\&rep=rep1\&type=pdf

Chennamaneni, A. (2006). Determinants of knowledge sharing behaviors: developing and testing an integrated theoretical model. The University of Texas at Arlington. https://rc.library.uta.edu/uta-ir/handle/10106/305

Chowdhury, S. (2005). The role of affect and cognition-based trust in complex knowledge sharing. Journal of Managerial Issues, 17(3), 310-326. 
Colquitt, J. A., Scott, B. A. y LePine, J. A. (2007). Trust, trustworthiness, and trust propensity: a meta-analytic test of their unique relationships with risk taking and job performance. Journal of Applied Psychology, 92(4). 909-927. https://doi.org/10.1037/0021-9010.92.4.909

Colquitt, J. A., Scott, B. A., Judge, T. A. y Shaw, J. C. (2006). Justice and personality: using integrative theories to derive moderators of justice effects. Organizational Behavior and Human Decision Processes, 100(1), 110-127. https://doi.org/10.1016/j.obhdp.2005.09.001

Cossons, N. (2006). Comunicating of Science: Science museums and exhibitions, European Commission Directorate-General for Research. Information and Communication Unit. http://ec.europa.eu/research/ rtdinfo/index_en.html

Cunha, M., Cunha, J. y Kamoche, K. (1999). Organizational Improvisation: What, When, How and Why. International Journal of Management Reviews, 1, 299-341. https://doi.org/10.1111/1468-2370.00017

Curtis, M. B. y Taylor, E. Z. (2018). Developmental mentoring, affective organizational commitment, and knowledge sharing in public accounting firms. Journal of Knowledge Management, 22(1), 142-161. https://doi. org/10.1108/JKM-03-2017-0097

Da Empoli, G. (2006). Comunicating of Science: Competing for attention, European Commission Directorate-General for Research. Information and Communication Unit. https://ec.europa.eu/dgs/competition/ economist/eagcp.html

Davenport, T. H. y Prusak, L. (1998). Working Knowledge: How Organizations Manage What They Know. Harvard Business School Press.

De Long, D. W. y Fahey, L. (2000). Diagnosing cultural barriers to knowledge management. Academy of Management Executive (19932005), 14(4), 113-127.

Delicado, A. (2009). Scientific controversies in museums: notes from a semi-peripherical country. Public Understanding of Science, 18(6), 759767. https://doi.org/10.1177/0963662508098577 
Dougherty, V. (1999). Knowledge is about people, not databases. Industrial and Commercial Training, 31(7), 262-266. https://doi.org/10. 1108/00197859910301962

Duffy, J. (2000). Knowledge management: to be or not to be? Information Management Journal, 34(1), 64-67.

Elangovan, A. R. y Karakowsky, L. (1999). The role of trainee and environmental factors in transfer of training: an exploratory framework. Leadership \& Organization Development Journal, 20(5), 268-275. https://doi.org/10.1108/01437739910287180

Fleck, J. (1996). Informal information flow and the nature of expertise in financial services. International Journal of Technology Management, 11, 104-28.

Foos, T., Schum, G. y Rothenberg, S. (2006). Tacit knowledge transfer and the knowledge disconnect. Journal of Knowledge Management, 10(1), 6-18. https://doi.org/10.1108/13673270610650067

Gibbert, M. y Krause, H. (2002). Practice exchange in a best practice Marketplace. En T. H. Davenport y G. J. B. Probst (eds.), Knowledge Management Case Book: Best practices (pp. 68-84), Publicis MCD.

Glaser, B. G. y Strauss, A. L. (1967). The discovery of grounded theory. Aldine Press.

Glicken, J. (1999). Effective public involvement in public decisions. Science Communication, 20(3), 298-327. https://doi.org/10.1177/107554709 9020003002

Goh, S. C. (2002). Managing effective knowledge transfer: An integrative framework and some practice implications. Journal of Knowledge Management, 6(1), 23-30. https://doi.org/10.1108/13673270210417664

Gold, A. H., Malhotra, A. y Segars, A. H. (2001). Knowledge management: an organizational capabilities perspective. Journal of Management Information Systems, 18(1), 185-214. https://doi.org/10.1080/0742122 2.2001.11045669 
Goman, K. C. (2002). Five Reasons People Don't Tell What They Know, Destination KM: Viewpoint (June). http://www.destinationkm.com

Gore, C. y Gore, E. (1999). Knowledge management: the way forward. Total Quality Management, 10(4-5), 554-560. https://doi. org/10.1080/0954412997523

Gurteen, D. (1999). Creating a Knowledge Sharing Culture. Knowledge Management Magazine, 2(5).

Hansen, M. T. (1999). The search-transfer problem: the role of weak ties in sharing knowledge across organization subunits. Administrative Science Quarterly, 44(1), 82-111. https://doi.org/10.2307/2667032

Hinds, P. J. y Pfeffer, J. (2003). Why organizations don't 'know what they know': cognitive and motivational factors affecting the transfer of expertise. En Sharing Expertise: Beyond Knowledge Management (pp. 3-26). MIT Press, Cambridge.

Huan, H., Yongyuan, M., Sheng, Z. y Qinchao, D. (2017). Characteristics of knowledge, people engaged in knowledge transfer, and knowledge stickiness: Evidence from Chinese R \& D team. Journal of Knowledge Management, 21, 00-00. https://doi.org/10.1108/JKM-02-2017-0054

Huber, G. P. (2001). Transfer of knowledge in knowledge management systems: unexplored issues and suggested studies. European Journal of Information Systems, 10(2), 72-79. https://doi.org/10.1057/palgrave. ejis.3000399

Huener, L., von Krogh, G. y Roos, J. (1998). Knowledge and concept of trust. En G. Krogh, J. Roos y D. Kleine (eds.), Knowing in Firms: Understanding, Managing and Measuring Knowledge (pp. 198-235). Sage.

Iftikhar, Z., Eriksson, I. V. y Dickson, G. W. (2003). Developing an instrument for knowledge management project evaluation. Electronic Journal of Knowledge Management, 1, 55-62.

Intezari, A., Taskin, N. y Pauleen, D. (2017). Looking beyond knowledge sharing: An integrative approach to knowledge management culture. Journal of Knowledge Management, 21. https://doi.org/10.1108/JKM06-2016-0216 
Ipe, M. (2003). Knowledge sharing on organizations: a conceptual framework. Human Resource Development Review, 2(4), 337-359. https:// doi.org/10.1177/1534484303257985

Iqbal, K y Dastgeer, G. (2017). Impact of self-efficacy and retention on transfer of training: The mediating role of motivation to transfer . Journal of Management Development, 36(10), 1270-1282. https://doi. org/10.1108/JMD-06-2015-0087

Janz, B. y Prasamphanich, P. (2003). Understanding the antecedents of effective knowledge management: the importance of a knowledge-centered culture. Decision Sciences, 34(2), 351-84. https://doi.org/10.1111/15405915.02328

Lam, A y Lambermont-Ford (2010). Tacit knowledge, organisational learning and societal institutions: an integrated framework. Organisation Studies, 21(3), 487-513.

Laspra-Pérez, B. (2013). El papel de los museos de ciencia y tecnología en los estudios demoscópicos de percepción social de la ciencia: El caso de España. Redes.com: revista de estudios para el desarrollo social de la Comunicación, 7, 123-140.

Lawrence, D. H. (2006). Comunicating Science: The abcs of communicating with the public: The power of emotions. European Commission Directorate-General for Research Information and Communication Unit B-1049 Brussels. http://ec.europa.eu/research/rtdinfo/index_en.html

Lecuona, J. R. y Reitzig, M. (2014). Knowledge worth having in 'excess': the value of tacit and firm-specific human resource slack. Strategic Management Journal, 35(7), 954-973.

Leonard, D. A. y Swap, W. C. (2005). When sparks fly: Harnessing the power of group creativity (Pbk. ed). Harvard Business School Press.

Leyland, M. L. (2005). The impact of trust and reputation on the transfer of best practices. Journal of Knowledge Management, 9(4), 87-101. https://doi.org/10.1108/13673270510610350 
Lin, C. P. (2007). To share or not to share: modeling tacit knowledge sharing, its mediators and antecedents. Journal of Business Ethics, 70(4), 411-428. https://doi.org/10.1007/s10551-006-9119-0

Lin, H.-F. (2007). Effects of extrinsic and intrinsic motivation on employee knowledge sharing intentions. Journal of Information Science, 33(2), 135-149. https://doi.org/10.1177/0165551506068174

Lin, H.-F. (2011). The effects of employee motivation, social interaction, and knowledge management strategy on KM implementation level. Knowledge Management Research \& Practice, 9(3), 263-275. https:// doi.org/10.1057/kmrp.2011.21

Lin, Y. y Dalkir, K. (2010). Factors affecting KM implementation in the Chinese community. International Journal of Knowledge Management, 6(1), 1-22. https://doi.org/10.4018/jkm.2010103001

Lindenberg, S. (2001). Intrinsic motivation in a new light. Kyklos, 54, 317-342. https://doi.org/10.1111/1467-6435.00156

Macdonald, S. (1998). Exhibitions of power and powers of exhibitions. En The politics of display: Museums, science, culture (pp. 225-237). Routledge.

Malhotra, Y. (1997). Knowledge Management in Inquiring Organizations. AMCIS 1997 Proceedings. https://aisel.aisnet.org/amcis1997/181

McKnight, D. H. y Chervany, N. L. (2001). What trust means in e-commerce customer relationships: an interdisciplinary conceptual typology. International Journal of Electronic Commerce, 6(2), 35-59. https://doi.or g/10.1080/10864415.2001.11044235

Menon, T. y Pfeffer, J. (2003). Valuing internal vs. external knowledge: explaining the preference for outsiders. Management Science, 49(4), 497-513. https://doi.org/10.1287/mnsc.49.4.497.14422

Nahapiet, J. y Ghoshal, S. (1998). Social capital, intellectual capital, and the organisational advantage. Academy of Management Review, 23(2), 242-66. https://doi.org/10.2307/259373 
Newman, B. y Conrad, K. W. (2000, 1 de abril). A Framework for Characterizing Knowledge Management Methods, Practices and Technologies. The Data Administration Newsletter.

Nichani, M. (2004). Understanding Organisational Culture for Knowledge Sharing, Australian Flexible Learning Community.

Nonaka, I. y Takeuchi, H. (1995). The Knowledge-creating Company: How Japanese Companies Create the Dynamics of Innovation. Oxford University Press.

Nonaka, I. A. (1994). A dynamic theory of organizational knowledge creation. Organization Science, 5(1), 14-37.

Osterloh, M. y Frey, B. S. (2000). Motivation, knowledge transfer, and organizational forms. Organization Science, 11, 538-550. https://doi. org/10.1287/orsc.11.5.538.15204

Osterloh, M., Frost, J. y Frey, B. (2002). The dynamics of motivation on new organisational forms. International Journal of the Economics of Business, 9(1), 61-77. https://doi.org/10.1080/13571510110102976

Pacharapha, T. y Vathanophas-Ractham, V. (2012). Knowledge acquisition: the roles of perceived value of knowledge content and source. Journal of Knowledge Management, 16(5), 724-739. https://doi. org/10.1108/13673271211262772

Polanyi, M. (1966). The Tacit Dimension. Routledge and Kegan Paul.

Razmerita, L., Kirchner, K. y Nielsen, P. (2016). What factors influence knowledge sharing in organizations? A social dilemma perspective of social media communication. Journal of Knowledge Management, 20(6), 1225-1246. https://doi.org/10.1108/JKM-03-2016-0112

Ren, X., Deng, X. y Liang, L. (2018). Knowledge transfer between projects within project-based organizations: The project nature perspective. Journal of Knowledge Management, 22(5), 1082-1103. https://doi. org/10.1108/JKM-05-2017-0184 
Rodari, P. y Merzagora, M. (2007). The role of science centres and museums in the dialogue between science and society. JCOM: Journal of Science Communication, 6(2), C01. https://doi.org/10.22323/2.06020301

Sánchez-Mora, M. (2004). Los museos de ciencia, promotores de la cultura científica. Elementos: ciencia y cultura, 11(53), 35-43. Benemérita Universidad Autónoma de Puebla.

Schein, E. H. (1985). Organizational Culture and Leadership. Jossey-Bass Publishers.

Schoorman, F. D., Mayer, R. C. y Davis, J. H. (2007). An integrative model of organizational trust: past, present, and future. Academy of Management Review, 32(2), 344-354. https://doi.org/10.5465/amr.2007.24348410

Stoddart, L. (2001). Managing Intranets to Encourage Knowledge Sharing: Opportunities and Constraints. Online Information Review. 25(1), 19-28. https://doi.org/10.1108/14684520110366661

Szulanski, G. (1995). Unpacking stickiness: an empirical investigation of the barriers to transfer best practices in the firm. Academy of Management Proceedings, 1995(1), 437-441. https://doi.org/10.5465/ ambpp.1995.17536715

Szulanski, G. (2000). The process of knowledge transfer: a diachronic analysis of stickiness. Organizational Behavior and Human Decision Processes, 82(1), 9-27. https://doi.org/10.1006/obhd.2000.2884

Szulanski, G. y Jensen, R. J. (2004). Overcoming stickiness: an empirical investigation of the role of the template in the replication of organizational routines. Managerial and Decision Economics, 25(6/7), 347-363.

Tangaraja, G., Mohd Rasdi, R., Ismail, M. y Abu Samah, B. (2016). Fostering knowledge sharing behaviour among public sector managers: a proposed model for the Malaysian public service. Journal of Knowledge Management, 19(1), 121-140. https://doi.org/10.1108/JKM-11-20140449 
Teo, T. S. H. y Liu, J. (2007). Consumer trust in e-commerce in the United States, Singapore and China. Omega, 35(1), 22-38. https://doi. org/10.1016/j.omega.2005.02.001

Testa, A. (2006). Comunicating of Science: Dialogue with society, Commission Directorate-General for Research. Information and Communication Unit, Brussels. https://www.livingknowledge.org/fileadmin/ Dateien-Living-Knowledge/Dokumente_Dateien/Toolbox/LK_C_Communicating_Science_Kit.pdf

Tsoukas, H. (2003). Do we really understand tacit knowledge? En M. Easterby-Smith y M. A. Lyles (eds.), Handbook of Organizational Learning and Knowledge (pp. 37-52). Blackwell Publishers. http://ec.europa.eu/ research/rtdinfo/index_en.html

Ulrich, D. (1998). Intellectual capital = competence $\times$ commitment. Sloan Management Review, 39(2), 15-26.

van den Hooff, B. y de Leeuw van Weenen, F. (2004). Committed to share: Commitment and CMC use as antecedents of knowledge sharing. Knowledge and Process Management, 11(1), 13-24. https://doi. org/10.1002/kpm.187

Wagner, R. K. y Sternberg, R. J. (1985). Practical intelligence in real-world pursuits: the role of tacit knowledge. Journal of Personality and Social Psychology, 49(2), 436-58. https://doi.org/10.1037/0022-3514.49.2.436

Zollo, M. y Winter, S. G. (2002). Deliberate learning and the evolution of dynamic capabilities. Organization Science, 13(3), 339-351.

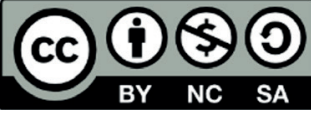

